\title{
AS RECENTES PERSPECTIVAS LEGITIMATÓRIAS DO JUDICIAL REVIEW NO CONSTITUCIONALISMO ATUAL DEMOCRÁTICO
}

\author{
THE RECENT LEGITIMATE PERSPECTIVES OF THE JUDICIAL REVIEW \\ ON DEMOCRATIC CURRENT CONSTITUTIONALISM
}

Larissa Waked Furtado ${ }^{1}$

\begin{abstract}
Resumo: Na contemporaneidade observa-se uma necessidade em relevar a legitimidade de juízes não eleitos para rever as disposições políticas tomadas na seara dos órgãos representativos de anseio popular. Nesta conjuntura, o problema aqui abordado sintetiza um conflito político entre as cortes judiciais e os campos legislativos que se encontram presentes em uma sociedade democrática como a brasileira. Portanto, com vistas a analisar o ambiente elementar do neoconstitucionalismo, bem como a sua plausível aparência na contemporaneidade, o presente estudo tem por objetivo revisar as atuais perspectivas legitimatórias do Judicial Review frente ao constitucionalismo atual democrático. Como justificativa para o desenvolvimento do presente estudo, observa- se que há distintos pontos de vistas acerca da probabilidade, bem como da validade dos tribunais constitucionais retirarem normas do ordenamento jurídico. Portanto, enxerga-se uma oportunidade de tratar acerca de análises que abordam um possível conflito existente entre o direito e a política no constitucionalismo hodierno. Esta pesquisa é de natureza qualitativa, do tipo exploratória-descritiva e utiliza como metodologia de pesquisa a revisão bibliográfica. Concluiu-se que a revisão judicial, um dos grandes focos de discussão na teoria constitucional norte-americana da segunda metade do século XX, amparada nas teses do constitucionalismo democrático e procedimentalista, robustece os valores democráticos a partir do neoconstitucionalismo, consolidando e efetivando os direitos básicos.
\end{abstract}

Palavras-Chave: Constitucionalismo; Democracia; Revisão judicial.

\begin{abstract}
Nowadays, there is a need to highlight the legitimacy of unelected judges to review the political provisions taken in fields representing the popular desire of the people. At this juncture, the problem addressed here synthesizes a political conflict between the judicial courts and the legislative fields that are present in a democratic society like the Brazilian one. Therefore, with a view to analyze the elementary environment of neoconstitutionalism, as well as its plausible appearance in contemporary times, the present study aims to review the current legitimate perspectives of the Judicial Review in view of the current democratic constitutionalism. As a justification for the development of this study, it is observed that there are different points of view about the probability, as well as the validity of the constitutional courts to withdraw norms from the legal system. Therefore, we see an opportunity to deal with analyses that address a possible conflict between law and politics in today's constitutionalism. This research is of a qualitative nature, exploratory-descriptive, using methodological bibliographic review. It was concluded that the judicial review, one of the major points of discussion in the North American constitutional theory of the second half of the 20th century, supported by the theses of democratic and proceduralist constitutionalism, strengthens democratic values from neoconstitutionalism, consolidating and enforcing rights basic.
\end{abstract}

Keywords: Constitutionalism; Democracy; Judicial Review.

\section{Introdução}

\footnotetext{
${ }^{1}$ Programa de Pós-Graduação em Direito, Faculdade de Direito, Universidade Portucalense, Porto, Portugal. email:larissa.waked@gmail.com
} 
Inicialmente, compete dizer que, frente ao panorama jurídico contemporâneo, os conceitos e sentidos de Constituição não computam tratamento padrão, despontando, assim, variações em consonância com a conjuntura e a tradição vivenciadas. Neste contexto, torna-se admissível apreender que os embasamentos do constitucionalismo atual se mostram inacabados para objetar os desafios do denominado "novo constitucionalismo", pois as modificações das dimensões políticas e geográficas, com a emergência de mercados comuns e o fim da bipolaridade do tempo da Guerra Fria, somados à discussão acerca da efetividade dos direitos fundamentais, acabam por reivindicar uma nova perspectiva argumentativa constitucional, progressivamente direcionada para a garantia de direitos individuais.

Diante disto, tem-se o judicial review (revisão judicial), que trata de um procedimento em que as ações executivas ou legislativas se encontram expostas à uma revisão do Poder Judiciário de determinado país: um tribunal, tendo a devida autoridade para revisão judicial, pode anular leis, atos e ações governamentais que se mostrem conflitantes com um comando superior. Desse modo, a revisão judicial é um dos freios e contrapesos na separação de poderes: o poder do judiciário de supervisionar os poderes legislativo e executivo quando estes excederem sua autoridade. A doutrina varia entre jurisdições, portanto, o procedimento e o escopo da revisão judicial podem diferir entre e dentro dos países.

Como problema do estudo, observa-se na contemporaneidade uma necessidade em relevar a legitimidade de juízes não eleitos para rever as disposições políticas tomadas na seara dos órgãos representativos de anseio popular. Nesta conjuntura, o problema sintetiza um conflito político entre as cortes judiciais e os campos legislativos de sociedades democráticas. Visando analisar o ambiente elementar do neoconstitucionalismo, bem como a sua plausível aparência na contemporaneidade, objetiva-se aqui debater as atuais perspectivas legitimatórias do judicial review frente ao constitucionalismo atual democrático.

A pesquisa aqui apresentada é de natureza qualitativa, do tipo exploratória-descritiva, com a coleta de informações posteriormente expostas e analisadas por meio da metodologia de revisão bibliográfica. Como justificativa para o desenvolvimento deste estudo, observa- se que há distintos pontos de vista acerca da probabilidade, bem como da validade dos tribunais constitucionais retirarem normas do ordenamento jurídico. Vislumbra-se aqui uma oportunidade de tratar acerca de análises que abordam um possível conflito existente entre o direito e a política no constitucionalismo hodierno.

Estruturalmente, a seção 1 trata da doutrina do Constitucionalismo, a seção 2 aborda a Revisão Judicial, a seção 3 apresenta a revisão judicial como essência do Constitucionalismo, a seção 4 aborda a legitimidade da revisão judicial. 


\section{Constitucionalismo}

Sabe-se que o constitucionalismo trata da doutrina de que a autoridade de um Governo é determinada por um corpo de leis ou constituição. Embora o constitucionalismo às vezes seja considerado sinônimo de Governo limitado, essa é apenas uma interpretação e, de maneira alguma, a mais importante historicamente. Em geral, o constitucionalismo refere-se a esforços para impedir um Governo arbitrário. No seu nível mais genérico, a arbitrariedade consiste na capacidade dos governantes de governar voluntariamente e de servir aos seus próprios interesses, e não aos dos governados. O constitucionalismo tenta evitar esses perigos projetando mecanismos que determinam quem pode governar, como e com que propósito.

No entanto, as tradições constitucionais diferem quanto ao que conta precisamente como um ato arbitrário e quais mecanismos oferecem a melhor defesa contra atos arbitrários que ocorram. A tradição republicana clássica, relacionada por seus intérpretes neorrepublicanos ao constitucionalismo político, identifica a arbitrariedade com a dominação dos governados por seus governantes e procura evitá-la estabelecendo uma condição de igualdade política, caracterizada por um equilíbrio de poder entre todos os grupos e partidos relevantes dentro de uma política, para que ninguém possa governar sem consultar os interesses dos governados (DALMAU, 2011).

De tal modo, ambas as tradições estão presentes na maioria das democracias e podem ser encontradas lado a lado em muitas constituições. A primeira tradição concentra-se no desenho e funcionamento do processo democrático, incluindo a seleção de sistemas eleitorais e a escolha entre formas presidenciais ou parlamentares de Governo, acordos unitários ou federais e unicameralismo, ou bicameralismo (DALMAU, 2012). Todavia, embora o detalhamento desses mecanismos processuais e as relações entre eles geralmente constituam a maior parte da maioria dos documentos constitucionais, sua importância constitucional passou a ser ofuscada particularmente nos círculos jurídicos - pela segunda tradição. Essa visão enfatiza a especificação e a proteção judicial das diferentes competências do sistema político e dos direitos constitucionalmente arraigados por um tribunal constitucional (BARBOSA, 2015)

Neste liame, teóricos políticos e cientistas discordam se essas duas tradições são complementares, implicadas entre si ou incompatíveis, com a segunda opção frequentemente vista como necessária para garantir a imparcialidade dos procedimentos e/ou os resultados da primeira (PASTOR, 2012). No entanto, abre-se, por sua vez, dúvidas sobre se os tribunais são, ou poderiam ser, verdadeiramente vinculados por constituições, para que a lei, em vez de os juízes, governem e, se for o caso, se os processos judiciais não são mais arbitrários e propensos 
a erro para decidir os resultados constitucionais do que os procedimentos e resultados democráticos que costumam ser legitimamente limitados (ARMENGOL, 2012).

É possível entender que o constitucionalismo é a ideia, frequentemente associada às teorias políticas de John Locke e dos fundadores da república americana, de que o Governo pode e deve ser legalmente limitado em seus poderes e que sua autoridade ou legitimidade depende de observar essas limitações. Essa ideia traz consigo uma série de questões de interesse não apenas para estudiosos do Direito, mas para qualquer pessoa interessada em explorar os fundamentos jurídicos e filosóficos do Estado. Uma constituição deve estabelecer uma estrutura estável para o exercício do Poder Público, que de alguma forma é fixado por fatores como significado público original ou intenções de autoria ou pode ser uma entidade viva que cresce e se desenvolve em conjunto com a mudança de valores e princípios políticos (DALMAU, 2011).

Em algum sentido mínimo do termo, uma constituição consiste em um conjunto de normas (regras, princípios ou valores) que criam, estruturam e, possivelmente, definem os limites do poder ou autoridade do Governo. Entendidos dessa maneira, todos os Estados têm constituições e todos os Estados são Estados constitucionais (SANTAMARÍA, 2011). Qualquer coisa reconhecível como um Estado deve ter algum meio de constituir e especificar os limites (ou a falta dele) impostos às três formas básicas de poder de Governo: Poder Legislativo (criação de novas leis), Poder Executivo (execução de leis) e Poder Judiciário (julgamento de disputas) (SANTOS, 2011).

Sendo assim, pode-se dizer que a constituição desse estado contém apenas uma regra, que concede poder ilimitado à Rex. Ele não é legalmente responsável pela sabedoria ou moralidade de seus decretos, nem é obrigado por procedimentos, ou quaisquer outros tipos de limitações ou requisitos, no exercício de seus poderes: tudo o que Rex decreta é constitucionalmente válido. Quando os estudiosos falam em constitucionalismo, no entanto, normalmente significa algo que descarta o caso de Rex. Significa não apenas que existem normas que criam poderes legislativos, executivos e judiciais, mas que essas normas impõem limites significativos a esses poderes. Frequentemente, essas limitações estão na forma de direitos civis contra o Governo, como liberdade de expressão, associação, igualdade e devido processo legal. Mas os limites constitucionais vêm de várias formas (PASTOR, 2012).

Eles podem se referir a coisas como o escopo da autoridade (por exemplo, em um sistema federal, governos provinciais ou estaduais podem ter autoridade sobre cuidados de saúde e educação, enquanto a jurisdição do Governo Federal se estende à defesa e transporte nacional); os mecanismos utilizados no exercício do poder relevante (por exemplo, requisitos processuais 
que regem a forma e o modo da legislação), e, claro, direitos civis (por exemplo, em uma Carta ou Declaração de Direitos) (DALMAU, 2011). O constitucionalismo é a ideia de que o Governo pode/deve ser limitado em seus poderes e que sua autoridade depende de observar essas limitações. Nesse sentido mais rico do termo, a sociedade de Rex não adotou o constitucionalismo porque a regra que confere seus poderes não lhes impõe limites constitucionais (ARMENGOL, 2012).

Ao discutir a história e a natureza do constitucionalismo, muitas vezes é feita uma comparação entre Thomas Hobbes e John Locke, que se acredita terem defendido, respectivamente, a noção de soberania constitucionalmente ilimitada. Mas um ponto focal igualmente bom é o teórico jurídico inglês John Austin que, como Hobbes, pensava que a própria noção de soberania limitada é incoerente. Para Austin, toda lei é o comando de uma pessoa soberana ou corpo de pessoas, e, portanto, a noção de que o soberano possa ser limitado por lei exige um soberano que seja auto vinculativo, que comande a si próprio.

Mas, ninguém pode comandar a si mesmo, exceto em algum sentido figurado, de modo que, para Austin e Hobbes, a noção de soberania limitada é tão incoerente quanto a ideia de um círculo quadrado. E embora uma vez esse recurso da teoria de Austin tenha alguma plausibilidade superficial quando aplicado ao sistema de Governo, o britânico por exemplo, onde o Parlamento costumava ser supremo e constitucionalmente ilimitado, ele enfrenta dificuldades óbvias quando aplicado à maioria das outras democracias constitucionais, como encontra-se nos Estados Unidos, Canadá, México e Alemanha, onde é abundantemente claro que os poderes do Governo são legalmente limitados por uma constituição (SANTOS, 2011).

Portanto, a resposta de Austin a essa aparente fraqueza em sua teoria foi apelar à soberania popular, a ideia de que o poder soberano reside, em última instância, no "povo", ou seja, na população em geral. Os órgãos governamentais - por exemplo, Parlamento ou Judiciário podem ser limitados pela lei constitucional, mas o povo, soberano, permanece ilimitado em seus poderes de comando.

\section{Judicial Review}

A judicial review (revisão judicial) trata da capacidade que o Judiciário tem de rever os atos dos demais poderes e determinar se tais ações são consistentes com a constituição. Ações julgadas inconsistentes são declaradas inconstitucionais e, portanto, nulas. A instituição da revisão judicial, nesse sentido, depende da existência de uma constituição escrita (CARNEIRO, 2015). O uso convencional do termo "revisão judicial" poderia ser descrito com mais precisão 
como "revisão constitucional", porque também existe uma longa prática de revisão judicial das ações de órgãos administrativos que exige que os tribunais não tenham o poder de declarar essas ações inconstitucionais nem que o país tem uma constituição escrita (CLÉVE \& LORENZETTO, 2016).

Assim, essa "análise administrativa" avalia as ações supostamente questionáveis dos administradores em relação aos padrões de razoabilidade e abuso de discrição. Quando os tribunais determinam que as ações administrativas contestadas são irracionais ou envolvem abusos de discrição, essas ações são declaradas nulas e sem efeito, assim como as ações julgadas inconsistentes com os requisitos constitucionais quando os tribunais exercem uma revisão judicial no sentido convencional ou constitucional.

Se um tribunal tem ou não o poder de declarar inconstitucionais os atos de agências governamentais, pode obter o mesmo efeito exercendo uma revisão judicial "indireta". Nesses casos, o tribunal declara que uma regra ou ação contestada não poderia ter sido pretendida pelo legislador porque é inconsistente com algumas outras leis ou princípios legais estabelecidos (CRISTÓVAM, 2015). A revisão judicial pode ser entendida no contexto de dois sistemas jurídicos distintos, mas paralelos - Direito Civil e Direito Comum - e também por duas teorias distintas da democracia sobre a maneira pela qual o Governo deve ser organizado com respeito aos princípios e doutrinas legislativas - supremacia e separação de poderes (DIMOULIS \& LUNARDI, 2016)

Primeiro, dois sistemas jurídicos distintos, o Direito Civil e o Direito Comum têm opiniões diferentes sobre a revisão judicial. Os juízes de Direito Comum são vistos como fontes de direito, capazes de criar novos princípios jurídicos e também de rejeitar princípios jurídicos que não são mais válidos. Na tradição do Direito Civil, os juízes são vistos como aqueles que aplicam a lei, sem poder para criar (ou destruir) princípios legais (GROSS, 2016). A ideia de separação de poderes é outra teoria sobre como o Governo de uma sociedade democrática deve ser organizado. Em contraste com a supremacia legislativa, a ideia de separação de poderes foi introduzida pela primeira vez por Montesquieu, mais tarde institucionalizada nos Estados Unidos pela decisão da Suprema Corte em Marbury versus Madison, sob a corte de John Marshall (KREUTZFELD, 2013).

A separação de poderes é baseada na ideia de que nenhum ramo do Governo deve poder exercer poder sobre qualquer outro ramo sem o devido processo legal: cada ramo do Governo deve verificar os poderes dos outros ramos do Governo, criando assim um equilíbrio regulatório e a chave para essa ideia são freios e contrapesos. Nos Estados Unidos, a revisão judicial é considerada uma verificação fundamental dos poderes dos outros dois ramos do Governo pelo 


\section{Judiciário (CLÉVE \& LORENZETTO, 2016).}

As diferenças na organização das sociedades "democráticas" levaram a diferentes pontos de vista sobre a revisão judicial, como as sociedades baseadas no direito comum e as que enfatizam a separação de poderes com maior probabilidade de utilizar a revisão judicial. No entanto, muitos países cujos sistemas jurídicos se baseiam na ideia de supremacia legislativa aprenderam os possíveis perigos e limitações de confiar o poder exclusivamente ao poder legislativo do Governo, assim como países com sistemas de Direito Civil adotaram uma forma de revisão judicial para conter a tirania da maioria (DIMOULIS \& LUNARDI, 2016). Outra razão pela qual a revisão judicial deve ser entendida no contexto do desenvolvimento de dois sistemas jurídicos distintos (Direito Civil e Direito Comum) e duas teorias da democracia (supremacia legislativa e separação de poderes), é que alguns países com sistemas de Direito Comum não possuem revisão judicial da legislação primária.

Embora um sistema de Direito Comum esteja presente em alguns lugares, como o Reino Unido, o país ainda tem um forte apego à ideia de supremacia legislativa; consequentemente, juízes no Reino Unido não têm o poder de derrubar a legislação primária. No entanto, desde que o Reino Unido se tornou membro da União Europeia, houve uma tensão entre sua tendência à supremacia legislativa e o sistema jurídico da União Europeia (UE), o que confere especificamente ao Tribunal de Justiça da UE o poder de revisão judicial (CARNEIRO, 2015).

Com isto, observa-se que a maioria dos sistemas jurídicos modernos permite que os tribunais analisem atos administrativos, que são decisões individuais de um órgão público, como uma decisão de conceder um subsídio ou retirar uma autorização de residência. $\mathrm{Na}$ maioria dos sistemas, isso também inclui a revisão do direito derivado, regras legalmente de aplicabilidade geral adotadas pelos órgãos administrativos).

Alguns países, como a França e a Alemanha, implementaram um sistema de tribunais administrativos encarregados de resolver disputas entre membros do público e da administração. Em outros países, incluindo Estados Unidos e Reino Unido, a revisão judicial é realizada por tribunais civis regulares, embora possa ser delegada a painéis especializados dentro desses tribunais, como o Tribunal Administrativo do Tribunal Superior da Inglaterra e do País de Gales (CLÉVE \& LORENZETTO, 2016).

Nota-se que os Estados Unidos empregam um sistema misto, no qual algumas decisões administrativas são revisadas pelos tribunais distritais dos Estados Unidos, que são os tribunais de julgamento geral. Algumas são revisadas diretamente pelos tribunais de apelações dos Estados Unidos e outras são revisadas por tribunais especializados como o Tribunal de Apelações dos Estados Unidos para Reivindicações de Veteranos que, apesar do nome, não faz 
parte tecnicamente do ramo judicial federal.

Existem três abordagens amplas para a revisão judicial da constitucionalidade da legislação primária, ou seja, leis aprovadas diretamente por uma legislatura eleita. Alguns países não permitem uma revisão da validade da legislação primária. No Reino Unido, os estatutos não podem ser anulados sob a doutrina da soberania parlamentar. Outro exemplo é a Holanda, onde a constituição pró́be expressamente os tribunais de se pronunciarem sobre a questão da constitucionalidade da legislação primária (GROSS, 2016).

Nos Estados Unidos, os tribunais federais e estaduais em todos os níveis, de apelação e de julgamento, são capazes de revisar e declarar a "constitucionalidade" ou acordo com a Constituição por um processo de interpretação judicial que é relevante para qualquer caso adequadamente dentro de sua jurisdição (KREUTZFELD, 2013). Sendo assim, é bastante comum que, antes que um pedido de revisão judicial de um ato administrativo, sejam apresentadas a um tribunal certas condições preliminares (como uma reclamação à própria autoridade) que devem ser cumpridas.

$\mathrm{Na}$ maioria dos países, os tribunais aplicam procedimentos especiais em casos administrativos. É comum afirmar que isso foi estabelecido no caso Marbury versus Madison, que foi discutido na Suprema Corte em 1803. Um sistema semelhante também foi adotado na Austrália. Portanto, nota-se que, na linguagem jurídica americana, revisão judicial refere-se principalmente à adjudicação da constitucionalidade dos estatutos, especialmente pela Suprema Corte dos Estados Unidos.

\section{Judicial Review: a essência do Constitucionalismo}

Nos países democráticos, sabe-se que o Judiciário reveste-se de grande importância. O principal papel do tribunal é o de resolver as disputas e dispensar a justiça entre um cidadão e outro. Mas os tribunais devem resolver as disputas entre o cidadão e o Estado, bem como os vários órgãos do Estado. Em muitos países observa-se que, constitucionalmente, prevalece a doutrina da revisão judicial. Isto significa que a constituição é a lei suprema e qualquer lei inconsistente com ela é nula. Os tribunais realizam o papel de expor as disposições da constituição e exercer o poder de declarar qualquer lei ou ação administrativa que seja inconsistente com a constituição.

Neste contexto, o tribunal pode declarar inválido qualquer exercício de poder se infringir qualquer disposição da constituição. Essa função judicial decorre do sentimento de que um sistema baseado na constituição escrita dificilmente pode ser eficaz na prática sem um árbitro 
autoritário independente e imparcial das questões constitucionais e também que é necessário restringir os órgãos governamentais de exercer poderes que não podem ser sancionados pela constituição. Sendo assim, a revisão judicial serve como uma verificação necessária para os possíveis excessos do legislador e do executivo (PIGNATARI, 2012).

Por exemplo, percebendo esses fundamentos filosóficos da constituição, a Constituição indiana fornece subsídios expressamente para a revisão judicial. A doutrina da revisão judicial tem sido usada pelo judiciário indiano com grande entusiasmo e sustenta a supremacia da constituição. Desde a independência até agora, o escopo de revisão judicial foi estendido repetidamente pelo Supremo Tribunal e pelo Supremo Tribunal da Índia para dentro de seu alcance (VICENTE \& ALEXANDRINO, 2015).

A revisão judicial é a doutrina da teoria democrática sob a qual a ação legislativa e executiva se mostra sujeita a invalidação pelo judiciário. É o exame, pelos tribunais de um país, das ações do legislativo, executivo e administrativo do governo, visando que essas ações estejam em conformidade com as disposições da constituição (BARROSO, 2010). Portanto, em outras palavras, é o controle de dois ramos do Governo (ou seja, o Executivo e Legislativo) pelo terceiro ramo (ou seja, o Judiciário) somente na medida em que suas ações sejam em conformidade e não violando a constituição

De tal modo, as ações que não estão em conformidade são inconstitucionais e, portanto, nulas. Como já visto, a prática é geralmente considerada como tendo começado com a decisão da Suprema Corte dos Estados Unidos em Marbury versus Madison. Várias constituições elaboradas na Europa e na Ásia após a Segunda Guerra Mundial incorporaram revisão judicial. Especialmente sujeitas a escrutínio nos EUA, foram ações relacionadas a direitos civis, liberdade civil, devido direito, igualdade de proteção nos termos da lei, liberdade religiosa, liberdade de expressão e direitos de privacidade (MASSON, 2020).

Analisa-se que a revisão judicial é um exemplo do funcionamento da separação de poderes em um Governo moderno, sistema no qual o Judiciário é um dos três ramos do governo. Este princípio é interpretado diferentemente em diversas jurisdições, que também têm visões diferentes sobre as diferentes hierarquias de normas governamentais. Como resultado, o procedimento e o escopo da revisão judicial diferem de país para país e Estado para Estado

Ao contrário dos EUA, a constituição da Índia estabelece explicitamente a doutrina da revisão judicial sob artigos como 13, 32, 131 a 136, 143, 226 e 246. A doutrina da revisão judicial é, portanto, firmemente enraizada na Índia e tem a sanção explícita da constituição. O Artigo 13 chega a dizer que o Estado não fará nenhuma lei que implique afastar ou abreviar os direitos conferidos por esta e qualquer lei feita em desacordo com esta cláusula na medida em 
que a contravenção seja anulada. Os tribunais da Índia estão, portanto, sob o dever constitucional de interpretar a constituição e declarar a lei como disposição inconstitucional.

A Suprema Corte declarou em State of Madras versus Row que a constituição contém o provisão para a revisão judicial do legislativo quanto à sua conformidade com a constituição e que o os tribunais enfrentam uma tarefa tão importante e nada fácil, não por qualquer desejo de se inclinar para o legislativo autoridade no espírito dos cruzados, mas no cumprimento do dever claramente estabelecido pela constituição.

O Tribunal Supremo de Goplalan versus Estado de Madras observou que, na Índia, é a Constituição que é lei suprema e estatutária para ser válida e deve, em todos os casos, estar em conformidade com os requisitos constitucionais, cabendo ao Judiciário decidir se qualquer emenda é constitucional ou não e se uma legislatura infringe qualquer limite constitucional que o tribunal tenha para declarar a lei inconstitucional. As doutrinas de supremacia da constituição foram expandidas com lucidez e força em Rajasthan versus Union of India, onde o tribunal observou que era necessário afirmar em termos mais claros, particularmente no contexto da história recente, que a constituição é suprema lex, a lei permanente da terra, e não há departamento ou ramo da Governo acima ou além dele.

Igualmente, todo órgão do Governo, seja ele Executivo, Legislativo ou Judiciário, deriva sua autoridade da constituição e deve agir dentro dos limites de sua autoridade. Ninguém, por mais altamente colocado, e nenhuma autoridade, por mais elevada que seja, pode afirmar que será o único juiz. na medida em que seu poder sob a constituição e sua ação está dentro dos limites de tal poder estabelecidos pela Constituição.

\section{A legitimidade do judicial review: os limites do diálogo entre tribunais e}

\section{legislaturas}

A teoria do "diálogo institucional", como se pode chamar, pode ser vista como uma contribuição canadense ao debate sobre a legitimidade democrática da revisão judicial. De acordo com essa teoria, os tribunais e as legislaturas participam de um diálogo sobre a determinação do equilíbrio adequado entre os princípios constitucionais e as políticas públicas e, nesse caso, há boas razões para pensar na revisão judicial como democraticamente legítima. É um diálogo contínuo, porque o judiciário não tem necessariamente a última palavra em relação a questões e políticas constitucionais. As legislaturas quase sempre teriam o poder de reverter, modificar ou anular uma decisão judicial que anula a legislação e, portanto, atingir seus fins de política social ou econômica. Consequentemente, a objeção contra majoritária à 
revisão judicial não pode ser sustentada.

A teoria do diálogo institucional emergiu conceitualmente da experiência do constitucionalismo canadense e à luz da prática constitucional sob a Carta Canadense de Direitos e Liberdades. A teoria afirma que essa forma de diálogo foi possível devido a várias disposições da Carta, sendo as duas mais importantes a cláusula de limitação e a cláusula de substituição (CHAVES \& ALMEIDA, 2015). De acordo com a cláusula de limitação, os legisladores têm direito constitucional de limitar por lei quaisquer direitos garantidos, desde que os limites cumpram um conjunto de requisitos justificativos que equivalem a testes complexos de legitimidade, racionalidade, necessidade e proporcionalidade (REIS, 2014).

Sob a cláusula de substituição, os legisladores estão constitucionalmente autorizados a anular por lei certos direitos garantidos específicos, desde que a lei predominante declare expressamente que não obstante as disposições que mencionam os direitos garantidos específicos relevantes (SCHELEDER \& ROBI FILHO, 2016). De tal maneira, percebe-se que alguém poderia acreditar que a teoria do diálogo institucional meramente descreve uma característica peculiar da estrutura constitucional canadense, o que seria errado. A teoria tem pertinência e apelo mais amplos. Por um lado, a ideia de que alguma forma de diálogo, discussão, comunicação, deliberação ou discurso possa conferir força legitimadora à autoridade política e à tomada de decisões tem sido um tema recorrente na legislação contemporânea. Por outro, um diálogo institucional pode ocorrer em qualquer lugar em que as legislaturas sejam capazes de reverter, modificar, evitar ou responder a decisões judiciais que anulam a legislação.

Em particular, pode ocorrer em qualquer jurisdição na qual a constituição contenha cláusulas de limitação explícitas ou na ausência de uma cláusula de limitação explícita enraizada na constituição, em que os tribunais tenham introduzido alguma forma de teste de equilíbrio para controlar a constitucionalidade das leis, limitando os direitos garantidos. De fato, segundo os teóricos do diálogo institucional, no Canadá, o diálogo institucional continuaria, principalmente sob a cláusula de limitação.

O problema de legitimidade levantado pela instituição de revisão judicial é bem conhecido. Está enraizado na suposição majoritária de que a fonte última de legislações legítimas em uma democracia reside na vontade da maioria do povo ou de seus representantes eleitos. Foi geralmente assumido, portanto, que a legislação, promulgada de acordo com a regra da maioria pelo povo ou por seus representantes eleitos é, em princípio, democraticamente legítima. Por outro lado, a revisão judicial envolve juízes que são capazes de anular a legislação promulgada democraticamente de acordo com a regra da maioria, e ainda assim esses juízes não são o povo nem são eleitos por eles; eles não representam os cidadãos e nem são 
responsabilizados por suas decisões.

Portanto, entende-se que esse "estado de coisas" é essencialmente contra majoritário. Segue-se, então, que a revisão judicial é democraticamente ilegítima, em princípio, e que o ônus de mostrá-la legitimamente repousa sobre aqueles que a consideram desejável. Para esse fim, várias estratégias foram propostas, que podem ser descritas de várias formas, baseadas na fonte, no processo ou na substância. Observa-se que a abordagem mais duradoura e relevante é a baseada na fonte. Postula-se que a revisão judicial pode ser legitimada se, e somente se, for possível demonstrar que, de certa forma, essa abordagem possui uma fonte democrática positiva.

No contexto atual, houve duas estratégias principais baseadas em fontes. A primeira constitui a ortodoxia predominante no Canadá, existente também nos Estados Unidos. A legitimidade da revisão judicial da legislação, nessa visão, reside no fato de que a constituição escrita, com base na qual a revisão judicial encontra sua autoridade, foi iniciada, desejada ou ratificada pelo povo ou por seus representantes eleitos. No Canadá, por exemplo, em uma decisão importante que trata da legitimidade da revisão judicial, a Suprema Corte disse que não se deve esquecer que a decisão histórica de entrincheirar a Carta na Constituição foi tomada não pelos tribunais, mas pelos representantes eleitos do povo do Canadá. Foram esses representantes que ampliaram o escopo do julgamento constitucional e confiaram aos tribunais essa nova e onerosa responsabilidade, sendo que o julgamento sob a Carta deve ser abordado livre de quaisquer dúvidas remanescentes quanto à sua legitimidade (D. V. B. SOARES, 2017).

Mas essa visão é incoerente. Na medida em que a estratégia postula que a democracia representa o princípio normativo final subjacente à legislação legítima, significa que o povo ou seus representantes eleitos não apenas têm o direito final de governar sua sociedade, ou seja, de fazer ou desarmar qualquer lei, mas também que eles têm o direito de mudar de ideia em relação a qualquer princípio legal e política social. Essa ideia é expressa na noção de soberania popular e requer que uma democracia seja contínua. Consequentemente, e por questão de princípio, os tribunais devem sempre defender a lei que melhor representa a vontade ou o consentimento das pessoas reais ou de seus representantes eleitos. Daqui se conclui que, onde houver um claro conflito de leis, eles deverão defender a lei que foi promulgada pelo posterior corpo democrático de cidadãos.

No entanto, a primeira estratégia afirma que seria moralmente admissível que os tribunais defendessem a vontade ou o julgamento de cidadãos passados - a fonte da linhagem democrática legitimadora - contra a vontade ou os julgamentos dos cidadãos atuais e, assim, limitassem seu poder a determinam democraticamente para si mesmos que tipos de políticas, 
valores, interesses e fins devem ser promovidos de acordo com seus próprios interesses.

A segunda estratégia pretende evitar essa incoerência. A legitimidade da revisão judicial, aqui, deriva do fato de que normas e valores constitucionais expressam um tipo de vontade coletiva que é democraticamente superior à vontade ou consentimento expresso em legislação comum. Essa estratégia pode assumir várias formas (CABRAL, 2013). De acordo com a noção de "dualismo democrático", por exemplo, a superioridade democrática da Constituição americana derivaria do fato de que seus valores são o resultado de raros momentos de legislações que consolidam os julgamentos considerados de uma massa de cidadãos mobilizados debatendo juntos, enquanto a legislação comum reflete apenas o trabalho diário dos políticos que falam através de instituições que, normalmente, não representam verdadeiramente os cidadãos. Assim, pode-se dizer que os tribunais, ao defender valores constitucionais contra alguma parte específica da legislação, frustram legitimamente a vontade dos representantes em nome do povo.

Outra forma desta segunda estratégia procede do que pode ser chamado de "dualismo democrático metafísico". Tal visão pressupõe, por exemplo, que exista uma tensão dentro de uma política democrática entre as pessoas "verdadeiras", que seriam racionais ou comprometidas com os propósitos autênticos da comunidade, e as pessoas "empíricas", aquelas que se expressam principalmente como eleitores em uma eleição e, muitas vezes, são guiados por suas emoções, interesses próprios, paixões, necessidades imediatas, retórica e conveniência em geral. Assim, onde algum exemplo de legislação comum seria inconsistente com os valores racionais das pessoas ou com os verdadeiros propósitos da comunidade, as pessoas "verdadeiras", embora teóricas, "realmente" desejariam anular as políticas que elas, manifestadas como eleitores, realmente deseja promover. Consequentemente, os tribunais teriam moralmente o direito de defender valores constitucionais contra legislação específica, pois estariam defendendo a "verdadeira" vontade do povo.

Essas versões das estratégias dualistas, assim como outras, podem ser questionáveis por seu mérito. Mas, mesmo sendo aceitáveis e coerentes internamente, dificilmente legitimam a instituição da revisão judicial. Primeiro, as estratégias não podem ter sucesso a menos que as normas expressas ou incorporadas na constituição escrita realmente restrinjam o processo de revisão constitucional. Caso contrário, os tribunais baseariam suas decisões em valores não expressos ou incorporados na constituição e, consequentemente, em valores não legitimados por sua estirpe democrática (SCHELEDER \& ROBI FILHO, 2016). Atualmente, é amplamente reconhecido que as disposições constitucionais são vagas e indeterminadas e é discutível, por exemplo, que a Suprema Corte do Canadá tenha rejeitado qualquer forma de formalismo 
jurídico com relação à interpretação constitucional. Portanto, argumentos democráticos baseados na fonte, dificilmente mostram que a revisão judicial é legítima: as estratégias descritas exigem que as normas constitucionais sejam esculpidas em um baldrame democrático.

Finalmente, mesmo se a constituição fosse democraticamente superior à legislação comum, não seria necessário que os juízes tivessem o poder de revisar a legislação. Na medida em que a legitimidade política é uma questão de linhagem democrática, parece que as legislaturas, e não os tribunais, devem ter moralmente o direito de tomar as decisões finais com relação à interpretação e aplicação constitucional - pela mesma razão pela qual melhor representam o povo. Essas estratégias parecem exigir supremacia legislativa, mesmo quando elas realmente procuram legitimar a supremacia judicial.

A teoria do diálogo institucional pode ser pensada como uma resposta às objeções anteriores; ou seja, a objeção do caráter contínuo da legitimidade democrática, a objeção da indeterminação e a objeção da supremacia judicial. Existem várias versões da teoria do diálogo institucional. No entendimento contemporâneo, a revisão judicial seria, por uma questão de fato empírica, parte de um "diálogo" entre os juízes e as legislaturas. Esse diálogo seria caracterizado pelo fato de que decisões judiciais baseadas na constituição, inclusive aqueles que derrubam a legislação quase sempre estão sujeitos à reversão, modificação ou evasão através do processo legislativo ordinário.

Todavia, embora os juízes possam avaliar a validade das leis de acordo com os valores da constituição, como as entendem, as legislaturas geralmente poderão respeitar os julgamentos judiciais ou corrigi-los, seja reformulando suas leis ou promulgando novas leis. As correções legislativas podem assumir várias formas. A Carta do Canadá, por exemplo, fornece quatro procedimentos, sendo os dois primeiros os mais importantes: 1) as legislaturas podem anular diretamente a decisão judicial que anula sua lei de acordo com a seção 33; 2) as legislaturas podem aprovar leis alternativas que atingir os objetivos legislativos da lei invalidada, ainda que por meios diferentes, de acordo com a seção 1 da Carta; 3) onde os direitos sejam "qualificados internamente", as legislaturas poderão aprovar novas leis que satisfaçam as exigências da Corte; 4) onde uma lei é derrubada com base nos direitos da igualdade, os legisladores têm uma variedade de medidas corretivas que lhes permitem definir suas próprias prioridades (SOARES, 2017)

De tal modo, as evidências empíricas que apoiam o diálogo institucional refutam a crítica da Carta baseada na legitimidade democrática. De fato, onde uma decisão judicial que estabelece uma lei com base na Carta pode ser revertida, modificada ou evitada por uma nova lei, qualquer preocupação com a legitimidade da revisão judicial é grandemente diminuída. A 
objeção baseada no caráter contínuo da democracia é refutada. Embora os tribunais possam anular a legislação com base nas opiniões dos cidadãos anteriores, suas decisões quase sempre deixam espaço para respostas legislativas contemporâneas. Da mesma forma, a objeção à indeterminação perde seu ponto de vista (CHAVES \& ALMEIDA, 2015)

Mesmo que os juízes fossem "ativistas" e aplicassem valores não consistentes com um entendimento "original" do texto ou não objetivamente comandado pelo texto, as legislaturas normalmente seriam capazes de conceber uma resposta que atinja os objetivos sociais ou econômicos que a decisão judicial impediu. Finalmente, a objeção da supremacia judicial é muito mais fraca do que se pensa (REIS, 2014). No entanto, embora os tribunais possam anular a legislação com base em seu próprio entendimento formal ou substantivo dos princípios e propósitos constitucionais, as legislaturas quase sempre podem reverter, modificar ou evitar suas decisões. Assim, como já foi observado, os tribunais não teriam a última palavra a respeito do equilíbrio adequado entre interesses individuais e políticas sociais e a constituição não seria necessariamente o que quer que os tribunais digam ser.

Daqui resulta que a revisão judicial raramente levantaria uma barreira absoluta aos desejos das instituições democráticas. Nesse sentido, não é antidemocrático. No final, se houver vontade democrática, o objetivo legislativo ainda poderá ser alcançado, embora com algumas novas salvaguardas para proteger os direitos e a liberdade individuais. Portanto, entende-se que a revisão judicial não é um tipo de veto sobre a política da nação. Além disso, a revisão judicial até aumentaria a democracia porque ocasionaria um debate público em que os valores da Carta teriam um papel mais proeminente do que teriam se não houvesse decisão judicial.

O conceito de diálogo pretende descrever todo o processo pelo qual a revisão judicial constitui o início de um diálogo sobre a melhor forma de conciliar os valores individualistas da Carta com a realização de políticas sociais e econômicas em benefício da comunidade como um todo. Argumenta-se que a experiência dos tribunais na interpretação dos direitos justifica que eles chamam a atenção do legislador para valores fundamentais que provavelmente serão ignorados ou refinados no processo legislativo, mas não na tentativa de terminar a conversa ou conduzir uma discussão, um monólogo em que as decisões da Carta são a palavra final (CABRAL, 2013). Assim, mesmo que as legislaturas sejam obrigadas a explicar explicitamente porque desejam limitar ou substituir certos direitos e liberdades, sua capacidade de responder ao Tribunal sem tentar restringir a Corte ou mudar a Constituição, como ocorreria sob o modelo americano de supremacia judicial, significa que a Corte não precisa ter a última palavra.

A teoria do diálogo institucional também foi endossada por outros juízes. No entanto, essa teoria foi vigorosamente criticada. Christopher Manfredi e James Kelly, por exemplo, 
provavelmente capturaram algumas das principais fraquezas de suas alegações empíricas. Segundo eles, a demonstração empírica da qual a noção de diálogo parece depender sofre de várias falhas (FADEEV \& SCHULZE, 2013). Em particular, alegam que muitas das sequências legislativas consideradas como evidência de diálogo podem ser consideradas simples atos de cumprimento de decisões judiciais e que a maioria das sequências legislativas envolveu mais do que pequenas alterações. Suas análises dos dados sugerem que o diálogo institucional é mais complexo e menos extenso do que o reivindicado por Hogg e Thornton (COLÓN-RÍOS, 2013).

Mas, a crítica mais importante para os propósitos do presente estudo se concentra nas reivindicações normativas da teoria do diálogo institucional. Segundo alguns, como Hogg e Thornton, a principal fraqueza da teoria, em uma perspectiva normativa, reside no fato de que ela mantém, de fato, a supremacia e a autoridade dos juízes em relação à interpretação constitucional. Por exemplo, Manfredi e Kelly argumentam que, além das alegações empíricas falhas, a metáfora do diálogo fornece apenas uma resposta fraca às questões normativas (FADEEV \& SCHULZE, 2013).

Mark Tushnet sustenta que o tipo de diálogo descrito por Hogg e Thornton distorce a política e debilita a democracia. Distorce a política porque as legislaturas podem adaptar os estatutos a normas de significado constitucional articuladas judicialmente, acreditar erroneamente que a política preferida está fora da faixa disponível ou modificar suas leis antes de uma decisão final do tribunal de apelação, onde existe a ameaça de reversão constitucional (COLÓN-RÍOS, 2013). Sendo assim, nota-se que esse tipo de diálogo pode debilitar a democracia porque implica subordinação (ou obediência) legislativa ao monopólio dos tribunais sobre a interpretação correta da constituição. Portanto, pode-se dizer que o diálogo genuíno só existe quando as legislaturas são reconhecidas como intérpretes legítimos da constituição e têm meios efetivos para afirmar essa interpretação.

\section{Conclusão}

Concluiu-se que a prática da revisão judicial das leis vem sendo atualmente um dos grandes focos da discussão na teoria constitucional norte-americana a partir da segunda metade do século XX. De um modo genérico, duas teses habituais surgiram como argumentos básicos para ratificar a legitimidade deste instituto aqui aludido: a tese do constitucionalismo democrático, e a tese procedimentalista. Na primeira, tem-se que a Constituição carregaria um valor essencial inerente, resultante do período democrático distinto atravessado em épocas de determinação constituinte, que precisa ser conservado pelo judicial review. Na segunda, a tese 
procedimentalista, que atém a competência das cortes para o judicial review ao amparo do próprio processo democrático e, do mesmo modo, procura impedir os desvios perpetrados no transcorrer da aceitação de leis no Congresso ou nas legislaturas estaduais.

Estas duas teses, assim sendo, robustecem valores democráticos assinalados. Enquanto a primeira observa a importância dos valores básicos expresso no documento constitucional, a segunda enxerga como fundamental a conservação da determinação democrática, como uma maneira de assegurar o princípio do autogoverno. Seguindo a lógica desenvolvida no transcorrer do presente estudo observou-se que, apesar as vozes opostas, o neoconstitucionalismo semelha agir de maneira contundente no sistema jurídico de muitos países, causando reflexos diretos na forma de interpretar a Constituição, bem como no desempenho da democracia, sem embargo dos alentos da globalização e das modificações causadas no padrão de Estado Constitucional.

Validamente, constatou-se que a sociedade constitucional, fundamentada em princípios, desponta na contemporaneidade com embasamento argumentativo e jurídico para a consolidação e efetividade dos direitos básicos, pois o valoramento dos itens normativos constitucionais, bem como a irradiação dos seus princípios e normas pelo sistema legal, através de procedimentos de ajuizamento e alegação, aplicadas por um Judiciário responsável e precavido às questões sociais, é apropriado de adjudicar preservação a deleções dos outros poderes no que se alude à contemplação de normas democráticas.

\section{REFERÊNCIAS}

ARMENGOL, C. M. V. (2012). El derecho constitucional del siglo XXI em latinoamérica: Un cambio de paradigma. In Estudios sobre el nuevo constitucionalismo latinoamericano. Tirant lo Blanc.

BARBOSA, M. L. (2015, fevereiro 19). Democracia direta e participativa: Um diálogo entre a democracia no Brasil e o novo constitucionalismo latino americano [DoctoralThesis]. UNIVERSIDADE FEDERAL DE PERAMBUCO. https://repositorio.ufpe.br/handle/123456789/15223

BARROSO, L. R. (2010). Interpretação e aplicação da constituiçãa: Fundamentos de uma dogmática constitucional transformadora ( $7^{\circ}$ ed). Saraiva.

CABRAL, B. F. (2013). Suprema Corte dos Estados Unidos: Temas Polêmicos. Editora Baraúna. 
CARNEIRO, B. L. V. (2015). O controle jurisdicional das políticas públicas: Possibilidades, limites e parâmetros. 65 .

CHAVES, C. T., \& ALMEIDA, G. A. de (Orgs.). (2015). Democracia e Subjetividade: Abordagens Interdisciplinares ( $1^{\mathrm{a}}$ edição). Editora D'Plácido.

CLÉVE, C. M., \& LORENZETTO, B. M. (2016). Governo democrático e jurisdição constitucional ( $1^{\mathrm{a}}$ edição). Fórum.

COLÓN-RÍOS, J. (2013). Beyond Parliamentary Sovereignty and Judicial Supremacy: The Doctrine of Implicit Limits to Constitutional Reform in Latin America. Victoria University of Wellington Law Review, 44, 521.

CRISTÓVAM, J. S. da S. (2015). Administração Pública Democrática e Supremacia do Interesse Público-Novo Regime Jurídico-Administrativo e seus Princípios Constitucionais Estruturantes-Apresentação de Ubaldo Cesar Balthazar-Prefácio de Humberto Ávila, José Sérgio da Silva Cristóvam. Juruá Editora. https://www.jurua.com.br/shop_item.asp?id=24063

DALMAU, R. M. (2011). El proceso Constituyente: La activación de la Soberanía. In Ahora és cuando, carajo? El viejo topo.

DALMAU, R. M. (2012). La naturaleza emancipadora de los procesos constituyentes democráticos: Avances y retrocesos. In Por una asamblea constituyente: Una solución democrática a la crisis. Ediciones Sequitur.

DIMOULIS, D., \& LUNARDI, S. G. (2016). Dimensões da constitucionalização das políticas públicas. Revista de Direito Administrativo, 273, 237-267. https://doi.org/10.12660/rda.v273.2016.66662

FADEEV, W. I., \& SCHULZE, C. (2013). Bundesverfassungsgericht und Gesetzgebung. In Verfassungsgerichtsbarkeit in der Russischen Föderation und in der Bundesrepublik Deutschland: Rundtischgespräch an der Moskauer Staatlichen Juristischen KutafinUniversität am 9. Und 10. Oktober 2012. Universitätsverlag Potsdam.

GROSS, A. F. (2016). Controle Judicial de Políticas Públicas: Uma abordagem a partir do Consequencialismo. Revista Jurídica da Procuradoria-Geral do Distrito Federal, 41(1), 150167.

KREUTZFELD, B. (2013). O ativismo judicial na implementação de políticas públicas. 
MASSON, N. (2020). Manual de Direito Constitucional (2020)_Editora Juspodivm. https://www.editorajuspodivm.com.br/manual-de-direito-constitucional-2020

PASTOR, R. V. (2012). Fundamento teórico del nuevo constitucionalismo latinoamericano. In Estudios sobre el nuevo Constitucionalismo Latinoamericano. Tirant lo Blanc.

PIGNATARI, A. A. C. G. (2012). Eficácia subjetiva das decisões judiciais no controle difuso-incidental de constitucionalidade. Revista da AJURIS, 39(125), 13-54.

REIS, I. C. (2014). Limites à legitimidade da jurisdição constitucional: Análise retórica das cortes constitucionais do Brasil e da Alemanha [DoctoralThesis]. Universidade Federal de Pernambuco. https://repositorio.ufpe.br/handle/123456789/11241

SANTAMARÍA, Á. (2011). El neoconstitucionalismo transformador: El Estado y el derecho en la Constitución de 2008. http://repositorio.uasb.edu.ec/handle/10644/2984

SANTOS, G. F. (2011). Neoconstitucionalismo, Poder Judiciário e Direitos Fundamentais ( $1^{\mathrm{a}}$ edição). Juruá Editora.

SCHELEDER, A. F. P., \& ROBI FILHO, I. N. (2016). Jurisdição Constitucional $\boldsymbol{e}$ Democracia. Editora da Univali. https://emporiododireito.com.br/leitura/livro-jurisdicaoconstitucional-e-democracia-disponivel-para-download

SOARES, D. V. B. (2017). Reconstruindo o conceito de independência judicial: um olhar realista sobre o lugar do supremo na política. https://core.ac.uk/reader/231259020

VICENTE, P., \& ALEXANDRINO, M. (2015). Direito Constitucional descomplicado. Forense. https://www3.livrariacultura.com.br/direito-constitucional-descomplicado-2112256374/p 